\title{
Awareness of International Students after Short-Term Intercultural Contact with Japanese Students: A Narrative Analysis of Dialogues with a Linguistic and Cultural Mediator
}

\author{
Yuri Okunishi, ${ }^{1,}$, Kosuke Fujiki' \\ ${ }^{1}$ Department of Secondary School Education, Faculty of Education, Okayama University of Science, Okayama City, Japan. \\ ${ }^{2}$ Center of Learning Support, Okayama University of Science, Okayama City, Japan.
}

\begin{abstract}
How to cite this paper: Yuri Okunishi, Kosuke Fujiki. (2020). Awareness of International Students after Short-Term Intercultural Contact with Japanese Students: A Narrative Analysis of Dialogues with a Linguistic and Cultural Mediator. The Educational Review, USA, 4(11), 185-192.

DOI: 10.26855/er.2020.11.001

Received: September 27, 2020

Accepted: October 20, 2020

Published: November 4, 2020

Corresponding author: Yuri Okunishi, Department of Secondary School Education, Faculty of Education, Okayama University of Science, Okayama City, Japan.

Email: okunishi@ped.ous.ac.jp
\end{abstract}

\begin{abstract}
This study investigated the dimensions of cultural awareness gained by international students in a cross-cultural international education program in a local Japanese community. Two international students, one from Italy and one from Indonesia, participated in the research. Their narratives arose in group interviews and were analyzed quantitatively using the M-GTA method. The analysis extracted four categories: excellent sociality, formation of unconstructive relationships, unique Japanese communication, and English language barrier. This paper discusses the possibility that international guests can simultaneously or sequentially experience adaptive and maladaptive psychological conditions through short-term close intercultural contact as well as the complexity of the path to cross-cultural adaptation. It also addresses the study's limitations and its implications for future research.
\end{abstract}

Keywords

Intercultural Contact, International Student, Japanese Culture, dialogue

\section{Introduction}

The rapid spread of COVID-19 around the world reminded us that the world truly is one "global village". Although the term "global village" often implies that people of the world could be harmonized as residents of the same planet, interdependence at the global level, without constructive intervention, often produces tensions and conflicts (Gojkov-Rajic \& Prtljaga, 2013). Past research on the relationships between cross-cultural residents, such as international students and immigrants, and members of the host society suggests that cultural understanding and adaptation to a host society is not a straightforward task. Previous research on international students in Japan reports that the longer international students stay in Japan, the more difficult it is for them to get along with Japanese hosts (Iwao \& Hagiwara, 1987). It has been reported that aspects that are specific to the Japanese culture may be difficult to understand or unacceptable for international sojourners (Nakano, Okunishi, \& Tanaka, 2015; Tanaka, 2000). These aspects include indirect expressions, reserved attitude, differentiated treatment toward foreigners, normative communication styles, and incomprehensively obscure rules (Okunishi \& Tanaka, 2008; Tanaka, 2000). Japanese hosts who have been in close contact with international students also recognize cultural differences, gaps in interactions, and associated psychological discomfort 
(Okunishi \& Tanaka, 2013). The question arises as to when and how psychological gaps originate in interpersonal relationships between international guests and Japanese hosts. Okunishi, Tanaka, and Inoue (2013) found that in very short periods of cross-cultural interactions between Japanese and foreign students, Japanese hosts found it difficult to envision or estimate potential cross-cultural conflicts. They tend to consistently respond to differences with a well-intentioned and innocent attitude. In other words, cultural differences, although recognized by Japanese individuals who were novices in intercultural contact, were not identified as problems to be solved. Bennett (1986) proposed the Development Model of Intercultural Sensitivity, which states that the experience of cultural differences varies depending on individuals' depths of intercultural experience. The extent to which people appreciate cultural differences is expressed as a continuum on which individuals possibly move from a lower stage to a higher stage as their intercultural sensitivity develops. The lower stages, labeled Ethnocentrism stages, constitute the Denial, Defense, and Minimization stages, whereas the higher stages, called Ethnorelativism stages, consist of the Acceptance, Adaptation, and Integration stages. Most Japanese, raised and living in a homogeneous society, may be culturally insensitive. Therefore, cognitive gaps may exist from the early stages of intercultural contact with their guests.

This study explores the mechanisms that would lead to obstacles in intercultural relationships and identifies the kind of mutual gaps that exist in intercultural understanding between Japanese individuals and international guests staying in Japan. This paper focuses on the cognitions of international guests toward the Japanese people and culture, who have been in close contact with Japanese individuals over a short period of time. Gaining a deeper understanding of the knowledge and perception of international students about the Japanese people and culture may help in understanding the need and potentiality of early interventions to facilitate interpersonal relationship formation between Japanese and foreign individuals. By closely examining the reflective narratives of foreign students enrolled in a 10-day educational volunteering program offered by a university in Japan, the nature of interactions and relationships between international and Japanese students are delineated.

The second author interviewed 2 international students and served as a linguistic and cultural mediator during the interviews. During the program, evening review interview sessions were held every 2 days, which involved an exchange of opinions between the mediator with an assisting student and the international students. Through the dialogues with the interviewer, narratives of interviewees were actively constructed. The interview method was based on the social constructivist position in which ideas are considered to be formed through dialogues (Suzuki, 2020). In other words, social reality is considered to be created through the processes of mutual dialogues. During the interviews, the interviewer, using words that aimed to promote multi-faceted thinking, encouraged the informants to think deeply about their experiences, and when judged necessary, conveyed Japanese ways of thinking and conducting things.

\section{Method}

\subsection{Participants}

The participants were 2 female students, from Italy and Indonesia, who had enrolled in a short-term summer educational volunteer program hosted by a university in western Japan. The Italian student was in her late adolescence, while the Indonesian student was in her early twenties. Both participants expressed an interest in the Japanese culture due to a boom in Japanese fashion, cuisine, and subculture (e.g., manga, popular dishes) in their home countries. They enrolled for the short-term volunteer program because they hoped to experience the Japanese culture close at hand. They applied for the program through a non-governmental organization, which aims to promote awareness about cultural diversity and peaceful coexistence. Prior to their visit, their face-to-face interactions with Japanese individuals were rather minimal. Therefore, their knowledge about the Japanese culture was acquired mainly through media, and their perceptions of the Japanese culture were more or less stereotypical.

\subsection{Procedure}

The authors explained the purpose of the study to the participants and assured them that their responses would remain confidential. The semi-structured interviews were conducted across the 10-day educational volunteer program, which was hosted in August 2019. The days on which the interviews were to be conducted were determined by identifying the potential turning points of the program. Accordingly, interviews were conducted on days 1, 2, 5, 7, and 9. Each interview lasted for approximately one hour. The interviews were conducted at the end of each of the aforementioned days, and the 2 students were simultaneously interviewed in a group interview format.

The basic questions in the interviews were drafted beforehand, and are as follows: "Have you got accustomed to the Japanese way of life?”; "Have you learned anything new or interesting about the Japanese culture?”; "How did you find 
out about it?"; "Did you have any trouble engaging in activities, or interacting with Japanese people?”; "Which behaviors do you expect Japanese students to exhibit during the next set of activities?”; "What did you gain from participating in this program?"; "According to you, what are the most significant cultural differences between Japan and Italy/Indonesia?”; and "Have your perceptions of Japanese students changed since the beginning of this program?”. When the discussion deepened, the interviewer allowed the conversation to flow naturally. Each interview was audio-recorded and subsequently transcribed verbatim.

The transcribed data were analyzed using the modified grounded theory approach (M-GTA) proposed by Kinoshita (2003). The M-GTA emphasizes on the elaborateness of the analytic procedure, unlike the original grounded theory approach (Glaser \& Strauss, 1967). Data for analyses are extracted based on the research theme. In the M-GTA, human perceptions, behaviors, emotions, and related factors and conditions are carefully examined in accordance with the data. Moreover, open coding in the M-GTA is guided by the analytical theme, which facilitates deeper interpretations of the data. The data fragments of interest to researchers should be examined with several possible interpretations from as many perspectives as possible and be validated against the data (Kinoshita, 2003).

The analyses of data in the M-GTA include several steps, such as identifying the analytical theme and analytically focused persons, developing an explanatory concept that may explain other similar expressions, and creating an analysis worksheet. As data analysis progresses, new concepts should be generated, and analysis worksheets should be completed for each concept. Simultaneously, the analyst should identify other specific examples that are embedded within the data and include them under the variations section of the worksheet. A concept for which several concrete examples fail to emerge should be regarded as invalid. Further, the generated concepts and other concepts should be examined in relation to each other. Finally, the analyst should develop a category that includes several conceptual relationships, summarize the results of the analysis based on the relationships among the categories, briefly describe the concepts, and create a results chart.

\section{Results}

The interview data were open coded. Ten concepts and four categories were extracted from the analysis of the foreign students' reflective narratives regarding the awareness of Japanese culture they acquired from short-term contact with Japanese students. The results of categorization were shown in Table 1 and the relationships among categories about cultural awareness by international students were shown in Figure 1. Table 1 shows the extracted concepts and categories along with concept definitions and examples of variations. Among the 4 categories, two were considered to be pertaining to helping international students adjust to Japanese society and culture, and another two were to be potential barriers to relationship formation with Japanese people. The sections below provide detailed explanations of the concepts obtained in each of the four categories.

The first category, "Excellent Sociality" included two concepts: "consideration of others" and "collective sociality". This study defined "consideration of others" as "awareness that Japanese people are naturally considerate of others". One informant stated:

I think, in general Japanese people were available to listen a lot to me when I made my presentation. In Italy, students are used to never listen. They're respectful for other people. This is a significant difference.

Through educational activities with Japanese students, the informants had multiple opportunities to feel respected and listened to by their Japanese colleagues, and to receive help and care from them. They also noticed that Japanese people show high levels of collective cohesive behaviors and that these behaviors enable each of them to contribute to final results in group settings. This study defined the concept of "collective sociality" as "awareness that Japanese people are highly socially engaged in groups and that they all contribute to their teams". The narrative example related to this concept is as follows:

I think Japanese also engage with team group. Everybody is giving, used to contribute. In my country, it is often that some people stay underside and talk to each other. Maybe it's like a coincidence. Just one time, but I've noticed that. When I was in school, I always hated team group because they were staying there and did nothing. Still, they got glory. However, in today's activities, I haven't seen that.

Thus, the informants perceived and appreciated Japanese students' highly engaged social behaviors. Sociality here refers to caring for others who were close to them and collective behavioral performance that resulted in high functionality and good outcomes in group activities.

The second category, "Unique Japanese Communication" included two concepts: "Japanese-style rituals of behavior" and "skillfully delayed self-disclosure". This study defined the first of these concepts as "awareness of and interest in 
peculiar Japanese behaviors that are performed in ritualistic manners”. The informants recognized signs and ritualistic behaviors that would help them become accustomed to the Japanese community. The related narrative example is as follows:

A random thing that I noticed that you do when you have a dialogue is that like you keep saying, "Hai, Hai, Hai" when the other person is. It is okay, like, for him to make sure that he knows that you are understanding and maybe, yeah, okay, I got it. We are not used to doing that.

This study defined the second concept in this category, "skillfully delayed self-disclosure", as "the discovery that Japanese people slowly reveal their individuality rather than not having any individuality or not disclosing themselves". This concept was identified based on the insightful observations of the informants regarding Japanese people's unique styles of self-disclosure. The narrative example is as follows:

I thought Japanese people really have a surface they show to the public, but they were not really expressing and people are kind of plain, but by staying with them and seeing them, they act when they are confident. You can see they are different and each of them has his own personality, its own qualities. Yes, I definitely changed my first impression. At first I was like so maybe I was kind of worried about it because everybody looks so unexpressed. But it is not like that. Maybe, it just takes time. Yeah.

The third category, "English Language Barrier" consisted of only one concept, “difficulty in communicating in English". This study defined this concept as "finding it difficult to achieve mutual understanding or share ideas because Japanese people's insufficient understanding of English served as a barrier". The informants had no previous experience learning Japanese, and English was supposed to function as the official language of communication during the project. While basic exchanges of information were possible between the international guests and their Japanese hosts, the Japanese students' limited English abilities made exchanging ideas, sharing ideas and feelings, and negotiating more difficult than simply exchanging information.

The fourth category was named as "Formation of Unconstructive Relationships". Although the informants recognized Japanese students' good manners and aptitude for forming human relationships, they also perceived certain unconstructive qualities that seemingly contradicted the qualities mentioned above. This category consisted of two concepts: "avoidance of confrontation" and "closed and reserved self". This study defined the first concept in this category, "avoidance of confrontation", as "awareness that Japanese people tend to avoid confrontational conversations, which can lead to unhealthy relationships caused by dysfunctional communication". The narrative example of this concept as follows:

Just like Cold War. Cold War. It is worse. My friends are better. We do not fight like this, yeah. In Indonesian culture, among boys, you have to fight like this, and problem solved, yeah.

After the interviewer, as a cultural mediator, explained possible reasons Japanese people favor indirect expressions and distanced interactions as communication methods, this informant insisted that she preferred the direct communication and interpersonal confrontation that usually takes place in her own culture. She contended that the silence kept by Japanese individuals in situations where conflicts need to be solved is worse than actually fighting and compared this phenomenon to what occurred during the "Cold War". Thus, the informants perceived the common modes of interaction among Japanese people-avoiding saying things that get to the heart of the matter, not seeking to solve problems, and focusing on maintaining relationships instead of developing them-as unconstructive.

This study defined the second concept in this category, "closed and reserved self", as "gaining an impression that Japanese people close themselves off to others, do not talk about themselves or familiar topics, or do not actively talk to others". The narrative example is as follows:

I was not asking, but I understand that it is a personal thing, also in my country, of course, it depends on personality. People open up and people don't open up but maybe, in general we are more open.

To propose possible gaps existing for international short-term guests in getting accustomed to Japanese culture, Figure 1 shows the relationships among the extracted categories. As Figure 1 shows, the international sojourners encountered Japanese people's high levels of sociality at relatively earlier stages. This sociality was characterized by Japanese people's sensitivity and consideration for other people, and had a non-verbal basis. The second stage the international guests encountered was a lack of constructiveness or fragility in human relationships within the Japanese solidarity framework. The informants assumed that the second stage of human relationships-which is based on open hearted dialogue and, in some cases, may be confrontational—was necessary for healthy and constructive relationship building. 
Table 1. Cultural Awareness of International Students During Short-Term Intercultural Contact in Japan

\begin{tabular}{|c|c|c|c|}
\hline Category & Concept & Definition & Example of Variation \\
\hline \multirow[b]{2}{*}{$\begin{array}{l}\text { Excellent } \\
\text { sociality }\end{array}$} & $\begin{array}{l}\text { Consideration } \\
\text { for others }\end{array}$ & $\begin{array}{l}\text { Awareness that Japanese } \\
\text { people are naturally consi- } \\
\text { derate of others; this in- } \\
\text { cludes respecting, listening } \\
\text { to, and helping others. }\end{array}$ & $\begin{array}{l}\text { I think, in general Japanese people were available to listen a } \\
\text { lot to me when I made my presentation. In Italy, students are } \\
\text { used to never listen. They're respectful for other people. } \\
\text { This is a significant difference. }\end{array}$ \\
\hline & $\begin{array}{l}\text { Collective } \\
\text { sociality }\end{array}$ & $\begin{array}{l}\text { Awareness that Japanese } \\
\text { people are highly socially } \\
\text { engaged in groups and that } \\
\text { they all contribute to their } \\
\text { teams. }\end{array}$ & $\begin{array}{l}\text { I think Japanese also engage with team group. Everybody is } \\
\text { giving, used to contribute. In my country, it is often that } \\
\text { some people stay underside and talk to each other. Maybe } \\
\text { it's like a coincidence. Just one time, but I've noticed that } \\
\text { When I was in school, I always hated team group because } \\
\text { they were staying there and did nothing. Still, they got glory. } \\
\text { However, in today's activities, I haven't seen that. }\end{array}$ \\
\hline \multirow[b]{2}{*}{$\begin{array}{l}\text { Unique } \\
\text { Japanese } \\
\text { communication }\end{array}$} & $\begin{array}{l}\text { Japanese-style } \\
\text { rituals } \\
\text { of behavior }\end{array}$ & $\begin{array}{l}\text { Awareness of and interest in } \\
\text { peculiar Japanese behaviors } \\
\text { that are performed in ritua- } \\
\text { listic manners. }\end{array}$ & $\begin{array}{l}\text { A random thing that I noticed that you do when you have a } \\
\text { dialogue is that like you keep saying, "Hai, Hai, Hai" when } \\
\text { the other person is, it is okay, like, for him to make sure that } \\
\text { he knows that you are understanding and maybe, yeah, okay, } \\
\text { I got it. We are not used to doing that in Italy. }\end{array}$ \\
\hline & $\begin{array}{l}\text { Skillfully } \\
\text { delayed } \\
\text { self-disclosure }\end{array}$ & $\begin{array}{l}\text { The discovery that Japanese } \\
\text { people slowly reveal their } \\
\text { individuality rather than not } \\
\text { having any individuality or } \\
\text { not disclosing themselves. }\end{array}$ & $\begin{array}{l}\text { I thought Japanese people really have a surface they show to } \\
\text { the public, but they were not really expressing and people } \\
\text { are kind of plain, but by staying with them and seeing them, } \\
\text { they act when they are confident. You can see they are dif- } \\
\text { ferent and each of them has his own personality, its own } \\
\text { qualities. Yes, I definitely changed my first impression. At } \\
\text { first I was like so maybe I was kind of worried about it be- } \\
\text { cause everybody looks so unexpressed. But it is not like that. } \\
\text { Maybe, it just takes time. Yeah. }\end{array}$ \\
\hline $\begin{array}{l}\text { English } \\
\text { language } \\
\text { barrier }\end{array}$ & $\begin{array}{l}\text { Difficulty in } \\
\text { communicating } \\
\text { in English }\end{array}$ & $\begin{array}{l}\text { Finding it difficult to } \\
\text { achieve mutual understand- } \\
\text { ing or share ideas because } \\
\text { Japanese people's insuffi- } \\
\text { cient understanding of Eng- } \\
\text { lish served as a barrier. }\end{array}$ & $\begin{array}{l}\text { Japanese students didn't understand so much my English, } \\
\text { maybe. I'm sorry because I found languages are barrier for } \\
\text { us to understand and to share things. (Asked if it was fru- } \\
\text { strating) Not frustrating, but I mean, I think it would be bet- } \\
\text { ter, if we had easier communication. Next time, I'll learn } \\
\text { Japanese more hardly. }\end{array}$ \\
\hline \multirow{2}{*}{$\begin{array}{l}\text { Formation of } \\
\text { unconstructive } \\
\text { relationships }\end{array}$} & $\begin{array}{l}\text { Avoidance of } \\
\text { confrontation }\end{array}$ & $\begin{array}{l}\text { Awareness that Japanese } \\
\text { people tend to avoid con- } \\
\text { frontational conversations, } \\
\text { which can lead to unhealthy } \\
\text { relationships caused by dys- } \\
\text { functional communication. }\end{array}$ & $\begin{array}{l}\text { Just like Cold War. Cold War. It is worse. My friends are } \\
\text { better. We do not fight like this, yeah. In Indonesian culture, } \\
\text { among boys, you have to fight like this, and problem solved, } \\
\text { yeah. }\end{array}$ \\
\hline & $\begin{array}{l}\text { Closed and } \\
\text { reserved self }\end{array}$ & $\begin{array}{l}\text { Gaining an impression that } \\
\text { Japanese people close them- } \\
\text { selves off to others, do not } \\
\text { talk about themselves or } \\
\text { familiar topics, or do not } \\
\text { actively talk to others. }\end{array}$ & $\begin{array}{l}\text { I was not asking but I understand that it is a personal thing, } \\
\text { also in my country, of course, it depends on personality. } \\
\text { People open up and people don't open up but maybe, in } \\
\text { general we are more open. }\end{array}$ \\
\hline
\end{tabular}




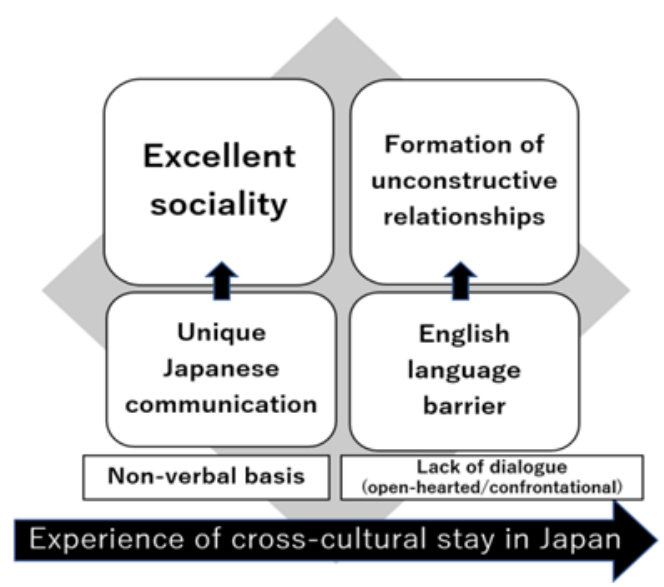

Figure 1. Relationships among categories about cultural awareness by international students.

\section{Discussion}

This study's analysis of the international informants' narratives revealed that they acquired complex insights about the impact of Japanese culture on interpersonal relationships during their very short visits. Interestingly, this analysis of informants' impressions from a short-term intercultural stay and close contact with host individuals helped creates a sample model regarding how Japanese society can foster a human environment that would meet the psychological needs of foreign guests and maximize the respective experiences of all sojourners by making host-guest relationships mutually fulfilling.

Through participation in group activities and close daily interactions, the short-term student visitors identified dedication and contribution to groups as well as thoughtfulness and consideration for others as strong and admirable cultural traits. This is related to cultural appreciation of Japanese people as highly social within their groups. It could be supposed that recognizing these aspects of Japanese culture could be an important first step towards intercultural adaptation to Japanese society for sojourners. At the same time, the student visitors also identified barriers that are innately embedded in Japanese people and society, including Japanese students' inability to communicate in English at deeper levels, as well as a lack of the open-minded dialogue skills needed to build up constructive relationships with others. The results indicated that international guests might experience adaptive and maladaptive mental conditions simultaneously or sequentially. Cross-cultural adaptation and cross-cultural maladaptation have typically been discussed in a binary fashion, but this phenomenon of adaptive and maladaptive attitudes appearing in the first few days of an international visit highlights the complexity of the path to cross-cultural adaptation. This slightly contradicts conventional culture shock and adaptation theories such as that of Oberg (1960), which holds that the first few days or weeks of cross-cultural stays comprise a "honeymoon stage" in which sojourners tend to see things with rosy glasses and are therefore in good psychological states; only after remaining in host countries for longer periods are they obliged to deal with real life conditions and try to overcome their specific discomforts and pains.

The progress of globalization makes various types of cross-cultural stays possible, and the widespread use of the Internet allows people to acquire preliminary knowledge about other countries, meaning that cultural learning takes place in various forms. Previous studies have reported that even relatively short opportunities for intercultural contact allow people to experience cultural learning and thereby help increase their intercultural knowledge, self-efficacy, and cultural intelligence (Church, 1982; Czerwionka, Artamonova, \& Barbosa, 2015; Nguyen, Jefferies, \& Rojas, 2018). Researchers have pointed out that the phenomenon of becoming multicultural cannot be explained simply as a psychological process of sequential adaptation to a new culture (Vora, Martin, Fitzsimmons, Pekerti, Lakshman, \& Raheem, 2018). Martin and Shao (2016) identified two types of multiculturals: innate multiculturals, who experience early immersion in cultures, and achieved multiculturals, who are exposed to multiple cultures and/or different cultural contexts. The latter's late-arriving culture learning necessitates the development of distinct cultural conditions that guide their interpretations as they switch between different cultural frames. Cultural learning may involve overcoming negative impressions and emotions even in short-term interactions, and can occur along different trajectories. Careful and close examination of the cultural learning phenomena of sojourners with different forms of cross-cultural experiences should further be explored.

After examining a community-based international educational program in Japan, Deguchi (2016) reported that 
short-term, close interactions between international and Japanese students enabled the participants to reach the stage of psychological unification in which they identified as an international entity, "we", with cultural awareness of simple "cultural differences". Nevertheless, the types of culture learning that could possibly lead international individuals to adapt to Japanese society in real situations require consideration.

Difficulties in communicating in English, perceived by international students as a "language barrier," may also be ascribed to Japanese students' communication style. Japanese is considered a high-context language (Yamashita, 2012), as characterized by subject omission, a lack of syntactic markers for gender and number, and so on. A higher dependency on the context of discourse also affects one's communication style, wherein the speaker relies more frequently on non-verbal cues than does a speaker of low-context languages such as English. The Japanese students participating in this short-term volunteer program have learned English in their six-year secondary education, and therefore have acquired the knowledge of the language to a considerable degree. Nevertheless, in their actual communication with international students, they encountered difficulties in expressing their thoughts clearly, resulting in communication breakdowns. For smoother communication in English, Japanese students will need to focus more on conveying their ideas verbally rather than simply expecting international sojourners to read between the lines. English classes can prepare them for diverse cultural contact by drawing their attention to different communication styles and other cultural differences. Although central to this study is cultural awareness among international students upon their contact with Japanese students, the findings also suggest that cultural awareness is important for the students of the host country as well. Opportunities for cultural contact, such as the one examined in this study, will encourage host students to gain an awareness of cultural differences.

The findings of this study have three potential applications. First, this study clarified the improvement and educational perspectives of Japanese hosts who accept short-term students in international education programs. This insight could enable organizers to develop effective cognitive-behavioral skill-building education for hosting students, which aims to improve these students' awareness of their own behavior and thinking patterns as well as their interaction skills. Second, even in cases where cognitive and skill-building education for hosting students related to communicative English and confrontational dialogue skills cannot be enhanced to the level required by short-term international guests, understanding the nature of the gap created by the interactions between foreigners and Japanese should enable program organizers or coordinators to pinpoint appropriate timing of psychological and educational interventions. Third, the findings gained from this study could be applied for the psychological support for intercultural adaptation of long-term foreign residents in Japan. The first possible stage would involve encouraging long-term residents to become aware of the nature of Japanese society and providing them with positive evaluation perspectives. In the second stage, a cross-cultural mediator could make international residents aware of the unique ways in which Japanese people relate to others and thereby help them realize the limits of the relationships they can build with Japanese people. Understanding these positive perspectives and limitations would enable international residents to find out the ways how they can relate to Japanese, while making use of the unique cultural characteristics they possess within themselves.

Authorities such as Japanese Ministry of Education, Culture, Sport, Science and Technology (2014) have discussed the necessity of improving Japanese students' English skill levels. However, the findings of this study suggest that English skills cannot only be conversational or mere communication skills but ones that would make dialogues possible between people with different cultural backgrounds. Hirata (2012) contended that the historical homogeneity of Japanese society hampered the development of the notion of dialogue among people of different backgrounds. Thus, psychoeducational exercises that present Japanese individuals with situations in which they cannot easily be understood without in-depth exchanging of words should be carried out in various settings. Gargen (2019) pointed out that when a person comes into contact with another group of people, the issue of "otherness" has to be faced. Attempts to develop appropriate psycho-educational interventions that invite people to face otherness and the implementation of action research will be required in the future.

Finally, the limitations of this study should be stated. The study only analyzed the narratives of two international individuals. Future studies should seek to verify the generalizability of these findings by increasing the number of subjects they examine.

\section{Acknowledgements}

This work was supported by JSPS KAKENHI Grant Number 17K02998.

\section{References}

Bennett, M. (1986). A developmental approach to training for intercultural sensitivity. International Journal of Intercultural Relations, 
10(2), 179-95.

Church, A. T. (1982). Sojourner adjustment. Psychological Bulletin, 91, 540-572.

Czerwionka, L., Artamonova, T., \& Barbosa, M. (2015). Intercultural knowledge development: Evidence from student interviews during short-term study abroad. International Journal of Intercultural Relations, 49, 80-99.

Deguchi, T. (2016). What do the participants of an International Volunteer Project Learn?: A Community of Practice Perspective. Multicultural Relations, 13, 19-31. (In Japanese with English abstract).

Gargen, J. K. (2019). An invitation to social construction (Higashimura, T. Trans.). Kyoto: Nakanishiya Publishing. (Original work published 1999)

Glaser, B., \& Strauss, A. L. (1967). The discovery of Grounded Theory: Strategies for qualitative research. Aldine Publishing Company, New York.

Gojkov-Rajic, A., \& Prtljaga, J. (2013). Foreign language learning as a factor of intercultural tolerance. Procedia-Social and Behavioral Sciences, 93, 809-813.

Hirata, O. (2012). Starting from not being able to understand each other—what is the ability to communicate? Kodansha Publishing, Tokyo. (In Japanese, translated by the authors of this article).

Iwao, S., \& Hagiwara, S. (1987). Images of Japan by foreign students in Japan (9): Differences by length of stay and Japanese language ability. Keio Univer sity Annual Review of Newspaper Research, 29, 55-75. (In Japanese, translated by the authors of this article).

Kinoshita, Y. (2003). Practice of Grounded Theory Approach. Kobundo Publishers Inc. (In Japanese, translated by the authors of this article).

Martin, L., \& Shao, B. (2016). Early immersive culture mixing: The Key to Understanding cognitive and identity differences among multiculturals. Journal of Cross-cultural Psychology, 47(10), 1409-1429.

Ministry of Education, Culture, Sport, Science and Technology-Japan. (2014). A Report on Measures to Improve and Enhance English Language Education in the Future: Five Proposals for English Language Education Reform in Response to Globalization, https://www.mext.go.jp/b_menu/shingi/chousa/shotou/102/houkoku/attach/1352464.htm (June 30, 2020) (In Japanese, translated by the authors of this article).

Nakano, S., Okunishi, Y., \& Tanaka, T. (2015). Interpersonal Behavioral Difficulties of Muslim Students in Japan during Intercultural Contact Situations. In Rogelia (ed.), "Enhancing quality of life through community integrity and cultural diversity: Promoting indigenous, social and cultural psychology", Progress in Asian Social Psychology Series, 10, 154-170.

Nguyen, A. D., Jefferies, J., \& Rojas, B. (2018). Short term, big impact? Changes in self-efficacy and cultural intelligence, and the adjustment of multicultural and monocultural students abroad, International Journal of Intercultural Relations, 66, 119-129.

Oberg, K. (1960). Cultural Shock: Adjustment to new cultural environments. Practical Anthropology, July-August, 177-182.

Okunishi, Y., \& Tanaka, T. (2008). Cultural support by Japanese host students: Investigation in supportive role for cross-cultural adjustment of international host students. Multicultural Relations, 5, 1-16. (In Japanese with English abstract).

Okunishi, Y., \& Tanaka, T. (2013). The coping styles among host families with intercultural contact in local international exchange: In search of a typology of naturally generated cultural learning. Journal of Qualitative Psychology, 12, 6-23. (In Japanese with English abstract).

Okunishi, Y., Tanaka T., \& Inoue, Y. (2013). The structure of learning in short-term host families: An analysis of cognitive and behavioral responses using the AUC-GS learning model. The Bulletin of Okayama University of Science, 49B, 25-34. (In Japanese with English abstract).

Suzuki, S. (2020). Discourse Analysis. In Sato, T, Kasuga, H. , \& Kanzaki, M. (Ed.), Qualitative research method mapping: To characterize and utilize(pp. 168-173). Tokyo: Shinchosha Publishing. (In Japanese, translated by the authors of this article).

Tanaka, T. (2000). Social networks and Social skills of international students. Nakanishiya Publisher. (In Japanese, translated by the authors of this article).

Vora, D., Martin, L., Fitzsimmons, S. R., Pekerti, A. A., Lakshman, C., \& Raheem, S. (2019). Multiculturalism within individuals: A review, critique, and agenda for future research. Journal of International Business Studies, 50, 499-524.

Yamashita, A. (2012). A study on Nikkei Hawaiian Japanese. Dialectologia, 9, 109-131. 